\title{
Methodological principles of forming multichannel digital communication in the supply chains
}

\author{
Vladimir Naumov ${ }^{1, *}$, Elena Naumova ${ }^{2}$, Evgeniy Shteyngart ${ }^{3}$, and Natalya Ostrovskaya ${ }^{4}$ \\ ${ }^{1}$ St. Petersburg State University of Economics (UNECON), 21, Sadovaya street, 191023, St. \\ Petersburg, Russian Federation \\ ${ }^{2}$ Saint Petersburg State Maritime Technical University, Lotsmanskaya Ulitsa, 10, 190121, St. \\ Petersburg, Russian Federation \\ ${ }^{3}$ Peter the Great St. Petersburg Polytechnic University, Polytechnicheskaya, 29, 195251, St. \\ Petersburg, Russian Federation \\ ${ }^{4}$ Financial University under the Government of the Russian Federation (Moscow) St. Petersburg \\ branch, Syezhinskaya Str., 15-17, 197198, St. Petersburg, Russian Federation
}

\begin{abstract}
Logistics is undergoing a digital transformation to manage material and intangible flows using various digital communication channels. In this regard, it is extremely urgent to develop a backbone and local IT platforms that unite participants in the supply chain to collect and analyze information for making optimal management decisions. The purpose of this study is to substantiate the main methodological principles of the formation of digital communications between participants in the supply chain to create an inter-corporate information and communication system. In preparing the material, such scientific methods as analysis and synthesis, process modeling, process method, and system approach were used. A model for organizing digital communication in the supply chain using the backbone communication IT platform is proposed. The role of digital trust in the organization of inter-corporate digital communication is shown, and the entropy factor is also taken into account when assessing the throughput of communication channels. The result of the study is the formulation and justification of methodological principles for the introduction of multichannel digital communication, providing not only electronic data exchange between logistics partners, but also reducing the logistic and transaction costs of supply chain participants.
\end{abstract}

\section{Introduction}

The rapid development of information and communication technologies has led to the need for digital transformation of the business processes of all participants in the supply chain. It is not only about the introduction of "heavy" software for managing material flows flowing through commodity distribution channels, but also about the "digitization" and integration of communication channels that provide for the collection and exchange of financial, logistic

\footnotetext{
* Corresponding author: sbe@ list.ru
} 
and marketing information for management decisions by participants in the supply chain. Various methodological aspects of the digital economy are considered from the perspective of the theory of logistics, human resource management and sharing-economy [1-4].

Digital communications - a set of contacts that ensure the interaction of various actors in the supply chain through digital channels, interested in the dissemination and receipt of relevant information. At the same time, a prerequisite that plays a fundamental role is consistency and integration between different channels. Note that in modern literature, instead of the concept of "contacts" are also used: "contact points" or "points of contact" (touch points).

With the help of special applications, logistics companies striving to increase their market stability can create a new and stronger customer base, increase customer satisfaction and quality of service $[5,6]$. In the context of the goal of the study, an IT platform can be used as an application, providing seamless inter-corporate digital communications along the entire supply chain.

As competition in commodity markets intensifies, the role of multichannel digital communication in organizing the interactive interaction of companies will only increase. In this regard, it is no coincidence that various aspects of the organization and management of communications between market entities attract the attention of many scientists and specialists in logistics and information technology [7-13], including a noticeable trend is the formation of multi-channel communication using various digital technologies and devices. According to Cook G., the consumer perceives these devices as a whole, which allows uninterrupted interaction with the seller and, thereby, facilitate the shopping process [14]. A particularly multichannel approach has become widespread in the retail sector, which is the final link in the supply chain in the B2C market. So, Verhoef P., Kannan P., Inman J. note that the advent of the online channel and new additional digital channels, such as mobile channels and social networks, have changed the retail business models, retail structure and customer behavior [15], and Zhag J., Farris P., Irvin J., Kushwaha T., Steenburgh T., Weitz B. believe that multichannelity can give a synergistic effect by optimizing points of contact with consumers [16]. Modern retailers offer customers channels that are currently widespread, including: a physical store, a catalog, a phone, an online store, and a mobile store.

It follows from the foregoing that the results of studies by various authors indicate the relevance of this issue, but, on the other hand, are fragmented. It requires the development of a methodological basis for the formation of multi-channel digital communication to ensure an interactive exchange of information between participants in the supply chain, which will increase their market stability and customer satisfaction, which form the demand for manufactured products. Consumers / buyers included in the supply chain should be grouped into segments according to criteria such as: diversity and assortment, quality / price and reasonable price segments reflecting the benefits provided by its participants. In this case, it is necessary to take into account trends in terms of the use of certain devices. For example, according to studies conducted by GfK, it showed that by the beginning of 2019 , "the proportion of Internet users on mobile devices has reached $61 \%$. A year earlier, this figure was $56 \%$. First of all, the growing audience of users who access the Internet only from a smartphone (35\%), and the use of tablets even slightly decreased compared to last year"[17].

The formation of multi-channel digital communications between participants in the supply chain will improve the management of tangible and intangible (informational, financial, etc.), which together should lead to a synergistic effect of economic indicators.

At the same time, there are a number of problems that are characteristic of many Russian industries, in terms of the practical use of the principle of multi-channel digital communications, which require certain organizational and technical solutions, including:

1. Insufficient penetration rate of the high-speed Internet of $4 \mathrm{G}$ generations (except for regional centers), and especially in terms of the quality and stability of signals of communication operators due to the "digital inequality" between different territories of the country. 
Note that the introduction of $5 \mathrm{G}$ generation mobile networks in Russia will significantly improve the quality and speed of digital communications in the $\mathrm{B} 2 \mathrm{C}, \mathrm{B} 2 \mathrm{~B}$ and $\mathrm{B} 2 \mathrm{G}$ markets for solving numerous commercial and social problems. However, the timing of the start of the introduction of this technology in Russia is not precisely defined, although according to some data they are indicated by the end of 2021.

2. The lack of "end-to-end" IT platforms connecting the supply chain participants with a single communication system that allows the exchange of relevant information online, including the use of web bots, artificial intelligence technologies, virtual reality, etc. This circumstance leads to digital information barriers between participants in the supply chain and the localization of relevant information. In essence, we can talk about "patchwork" communication either within the company, or only between the two closest participants in the supply chain.

3. Lack of resources (financial, technological, human) and competencies for implementing digital transformation projects not only for an individual company, and most importantly, for creating a "seamless" digital communication between all participants in the supply chain.

4. An insufficient level of "digital" trust in the implementation of interactive digital-communications, especially when carrying out transactions of participants in the supply chain.

5. Lag behind the leading foreign countries in the development of competitive information technologies.

To the above, an important problem must be added regarding the use of Western communication equipment and software, as well as the choice of location of servers, data centers (data centers), etc. So, on November 29, 2018, the software expert council under the Ministry of Communications of the Russian Federation decided to phase out the use of software based on foreign platforms. The regulator recommends the owners of such software to transfer it to domestic platforms and limit the purchase of imported software for state organizations and companies with state participation.

In this regard, there are risks of digital transformation of domestic enterprises, the needs of which may not be satisfied only by domestic software. To reduce risks in the transition to a new technological structure in the Russian economy, it is necessary to create an ecosystem in the form of strategic interaction between state institutions, business and scientific organizations, the main task of which is the development and implementation of "end-to-end" integrated information technologies that are not competitive only in the national market, but also internationally.

The problems discussed above require a quick solution, since they significantly reduce the effectiveness of communications needed to coordinate production, distribution, logistics in the implementation of a commodity-money exchange between participants in the supply chain and are a brake on the development of the country's economy as a whole.

\section{Materials and methods}

The relevance of introducing multi-channel digital communications into the practice of supply chain functioning has led to numerous publications by scientists conducting research in the field of logistics, management, marketing, customer relationship management in the retail industry, etc.

Within the framework of the problems under consideration, publications of Beck N., Rygl D. [7], Cao L., Li L. [9], Herhausen D., Binder J., Schoegel M. [12], Manser Payne E., Peltier J., Barger V. [18], Verhoef P., Kannan P., Inman J. [15], devoted to the study of various aspects of the functioning of multi-channel systems in the retail industry. In a number of publications, multichannel communication systems are considered from the point of view of impact on consumer behavior, marketing activities of the company [19-21] and on the business as a whole [22-23]. The results obtained in [24] showed a positive and significant impact 
of the three methods of rational supply chain management on the company's market performance, namely: the JIT system, information flow and customer relations. In this regard, we note that, in general, in the theory of supply chain management, little attention has been paid to the formation and management of information flows using end-to-end IT systems, which indicates the relevance of this topic.

In preparing the material for this article, such scientific methods as analysis and synthesis, process modeling, process method, and system approach were used.

Using analysis as a method of scientific research, it was possible to consider the supply chain as a set of individual elements that perform certain logistics, commodity distribution and communication functions.

The synthesis method was used as a scientific tool for combining the communication processes that take place between participants in the supply chain.

Using modeling and a process approach allowed us to display the complex organizational structure of the supply chain in the form of series-connected block elements with communicative connections and, at the same time, preserve a certain similarity of the supply chain to solve the research problem.

The systematic approach made it possible to identify and consistently consider the methodological principles of the formation of multi-channel digital communications in the $\mathrm{B} 2 \mathrm{C}$ and $\mathrm{B} 2 \mathrm{~B}$ markets.

\section{Results}

The rapid development of information and communication technologies allows us to solve a number of problems in the field of organizing digital communications between participants in the supply chain, not only on the "short" shoulder, but also to create backbone IT systems connecting manufacturers, starting from the production of raw materials and materials ending with the release of finished products. For these purposes, cloud technologies, Big data, blockchain, integrated IT platforms can be used. Powerful computer centers are being intensively built, which allow collecting and analyzing data, including the exchange of various information between participants in the supply chain.

Currently, companies organize the collection and analysis of information using, for example, applications of the MRP and CRM classes, carry out information exchange with other participants in the supply chain, mainly by e-mail. To improve the efficiency of the logistics, financial and marketing processes, this is now clearly not enough, it is necessary to implement multi-channel digital communications, which will more accurately manage demand in the supply chain, and increase the satisfaction and loyalty of its end-user customers. Essentially, we are talking about introducing integrated communication channels, which allow us to better monetize the relationship between buyer and seller and increase added value.

At the same time, there is still no methodology for designing complex software tools for organizing backbone digital communications, which play a key role in optimizing information flows according to the criterion of reducing operating costs, both in the manufacturing and circulation sectors.

This scientific problem attracts the attention of many scientists and practitioners, since the management of digital communications on the "long" shoulder will contribute to a more rational use of logistic resources available in the distribution channels, more accurate planning of production activities of enterprises that supply their products not only to domestic market, but also to foreign markets. In this regard, it is advisable to formulate methodological principles for the formation of digital communications as follows:

1. The principle of software congruence, primarily in the sales channels of each manufacturing enterprise that is part of the supply chain. In this case, we mean the correspondence 
and consistency of the parameters of communication equipment installed at any enterprise, the "seamlessness" of software algorithms, etc.

2. The principle of the backbone of the information and communication system that provides multi-channel digital communications along the entire length of the supply chain.

3. The principle of "digital" trust between all participants in the supply chain, which allows to accelerate and simplify decision-making in the field of digital interaction of market entities included in the supply chain.

4. The principle of multi-channel digital communication to ensure quick access to receive and send information to any participant in the supply chain from any technical device (device).

The first principle includes mainly organizational and technical issues that can be implemented if there is a strategic level partnership between the supply chain participants and they are ready to make mutual investments in the organization of multi-channel digital communications.

From a technical point of view, the channels providing digital communications should be proportionate in terms of throughput of information traffic passing through the gateways and switching nodes of electronic networks. The bandwidth of any k-th channel of digital communication $(\mathrm{Ck})$ is equal to the maximum traffic at the input and output of the information system of each participant in the supply chain, taking into account the effect of entropy, as a measure of the uncertainty of the transmitted information:

$$
\mathrm{Ck}=\max (\text { Tonj })_{\mathrm{k}} / \text { ton }=\max (\text { Tinj-Einj })_{\mathrm{k}} / \mathrm{tin},
$$

where Tinj, Tonj - traffic volumes of incoming (Tinj) and outgoing (Tonj) information of the j-th participant in the supply chain; Einj - entropy showing how much of the transmitted information on the communication channel " $k$ " has uncertainty or is lost altogether by the $\mathrm{j}$ th participant; ton, tin - time periods of the passage of traffic of incoming and outgoing information flows of the $\mathrm{j}$-th participant in the supply chain.

Thus, the bandwidth (power) of the channel is the upper limit of the amount of transmitted information per unit time, which should have the lowest possible level of entropy.

By measuring the current volume of traffic on digital communication channels, which will be less than its bandwidth, you can calculate the utilization rate of the channel's communicative traffic:

$$
\alpha=\mathrm{C}_{\mathrm{t}} / \mathrm{C}_{\mathrm{k}},
$$

where $\alpha$ is the utilization rate of the communicative channel traffic; $\mathrm{Ct}$ is the current volume of information traffic on the $\mathrm{k}$-th communication channel.

It follows that the digital communication process should be organized in terms of choosing the most efficient information transmission channels that provide maximum throughput with a minimum level of uncertainty, based on the needs of all participants in the supply chain. It should be noted that the creation of an information-oriented network, according to some scientists, is an innovative paradigm for the future Internet architecture, which takes into account the limitations of the IP network in supporting the distribution of content and access to information.

The second principle means the creation of a backbone system that ensures the transmission of information along the entire length of the supply chain and can be implemented using the process method by constructing a model of digital communications. An example of a digital communications model using an IT backbone platform is shown in Figure 1. 


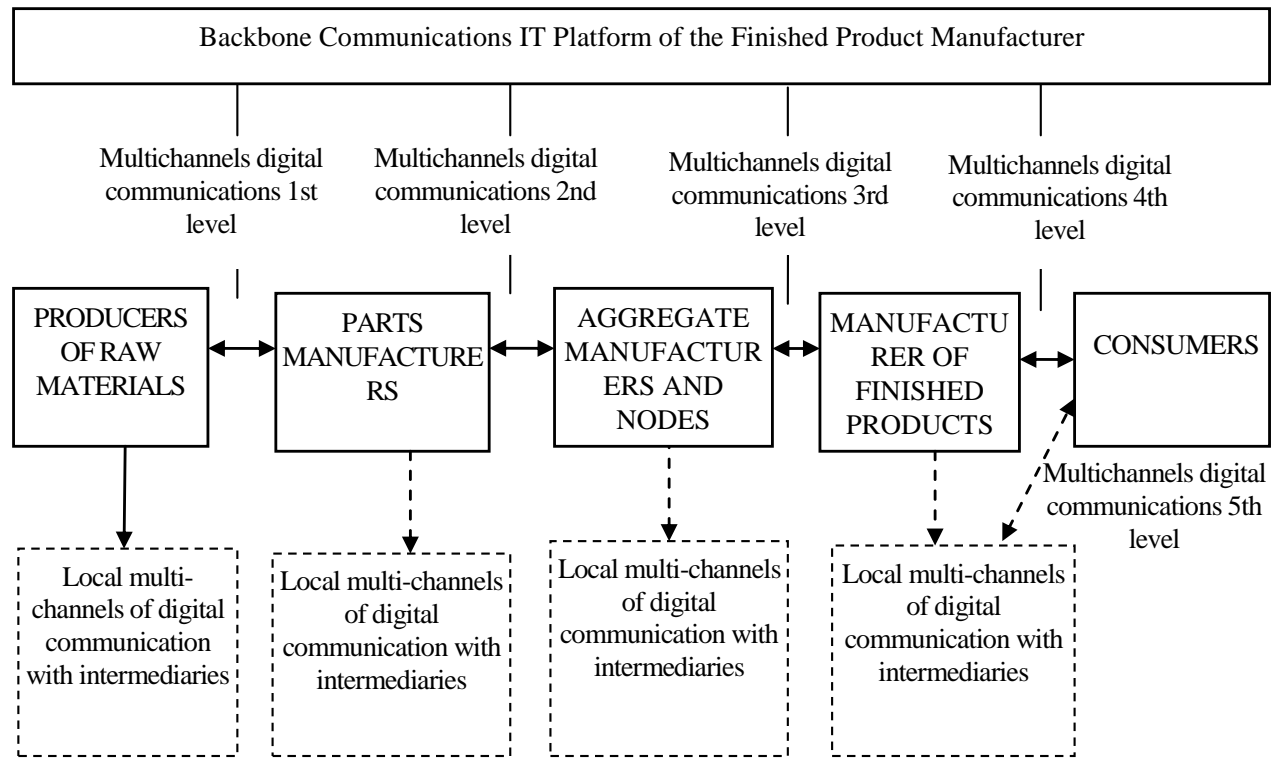

Figure 1. A model for organizing digital communication in the supply chain using the backbone communication IT platform (developed by the authors).

The presented model (Figure 1) shows that digital communications are carried out between manufacturers at each level of the supply chain, starting from suppliers of raw materials and ending with the manufacturer of finished products. To coordinate information flows, the finished goods manufacturer creates an IT backbone platform, thereby ensuring "seamless" communication with each participant in the supply chain.

In turn, manufacturing enterprises that are part of the supply chain carry out local digital communications with their intermediaries operating in their distribution channels (Figure 2).

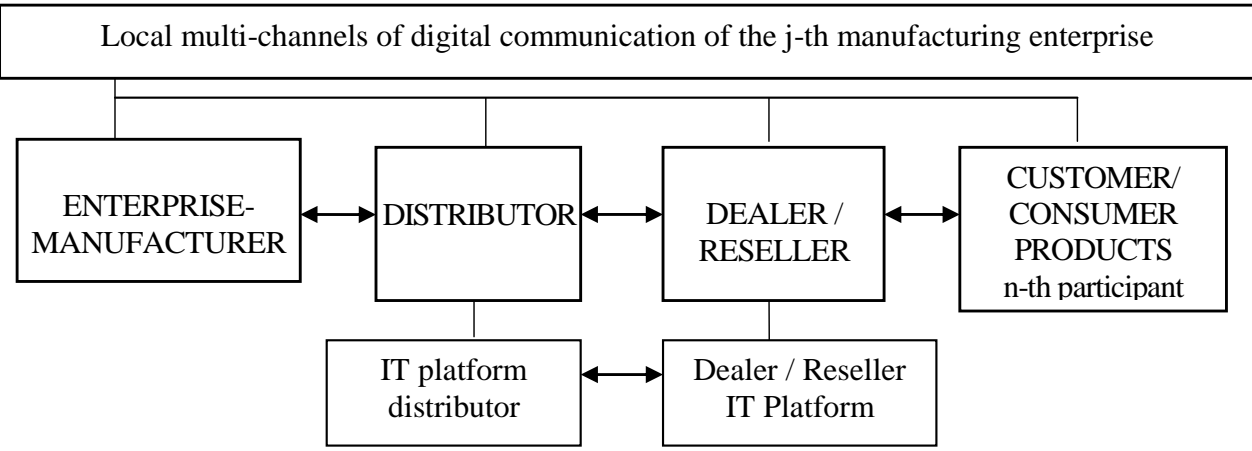

Figure 2. A model for organizing local digital communications in the sales channel of a supply chain manufacturer (developed by the authors).

From the presented Figure 2, it follows that manufacturing enterprises that are part of the supply chain accumulate and process information received from their distributors and dealers / resellers using a local electronic network, and after analysis transfer it to a common inter- 
company backbone IT platform. This model essentially implements the principle of EDI technology, which allows for the exchange of data in a standardized electronic format.

As a result of repeated contacts made using digital communication channels, relationships are formed, the strength of which depends on the form and volume of mutual obligations. Finally, in the process of strengthening relationships, relationships appear that are the basis for further co-investments.

The introduction of backbone and local communication IT platforms in the supply chain will require a number of steps.

\section{Pre-investment phase:}

1. The readiness of the companies participating in the supply chain for a strategic partnership to create a multi-channel digital communications system is assessed.

2. A business project is being developed with a forecast of expenses and revenue, determination of the required financial, technical and human resources.

3. The resources and competencies at the disposal of the companies are evaluated.

4. Investment contracts for joint activities for the implementation of this project are concluded.

\section{Investment stage:}

5. The necessary points of contact are identified, a travel map of the participants of the supply chain is compiled, the required types of digital communication channels are determined to create an information and communication platform.

6. A structure is being created to manage communication channels for the interaction of supply chain participants (contact center, Big date, etc.).

7. Procedures and protocols for the interaction of supply chain participants in digital communication channels are being developed. If necessary, the multichannel system should provide communications with the company's logistics and service departments.

\section{Work Stage:}

8. An automated system for collecting and processing data received in digital communication channels is launched.

9. The calculations of the effectiveness of the communication process and the work of the contact center employees are carried out.

In the framework of the implementation of the third principle (digital trust), it is necessary:

- ensure information security of the information corporate network;

- build confidence in the information exchanged by participants in the supply chain;

- establish trusting interpersonal relationships between employees of companies included in the supply chain.

Due to the growing number of cybercrimes in various fields, the level of concern about industrial espionage, the safety of personal data is growing, and as a result, the factor of trust is acquiring strategic importance. It is no coincidence that in May 2018 the St. Petersburg International Economic Forum was held under the motto "Creating an Economy of Confidence". Experts at the PWC consulting company rightly believe: «If the circulatory system of the digital economy is data, then the credibility of digital technology is its heart. It is about the level of confidence in people, processes and technologies that is necessary to build a safe digital world» [25]. Digital trust between participants in the supply chain is regulated through the development of general privacy rules and access rights, information protection, digital signatures, etc. The role of the personality factor is that a person better perceives information from a person whom he knows and trusts.

Thus, digital trust and communication are important elements in the formation of relations between subjects of market relations in the digital environment.

To assess the quality of digital communications of supply chain participants, the following characteristics can be distinguished: 
- The value and accuracy of the transmitted information through different channels of digital communication;

- speed and throughput of digital communication channels in the supply chain;

- "Seamlessness" of IT platforms of supply chain participants for information exchange;

- A high level of digital trust in the process of exchanging information.

Fourth principle - organization of multi-channel digital communication to provide quick access to receive and send information to any participant in the supply chain.

The development of backbone and local IT systems should include the possibility of using several channels of digital communications for the interaction of suppliers of goods or services, customers and consumers, including online. Thanks to the Internet, participants in the supply chain are able to interact interactively (contacts) with each other using a variety of communication tools and channels (table 1).

Table 1. Tools and channels digital communications for making contacts.

\begin{tabular}{|c|c|c|}
\hline Contact forms & Means of communication & Communication channels \\
\hline Not personal contacts & $\begin{array}{l}\text { - blogs; } \\
\text { - posts; } \\
\text { - chats (including video chats); } \\
\text { - tweets; } \\
\text { - wiki; } \\
\text { - other }\end{array}$ & $\begin{array}{l}\text { - sites (including: } \\
\text { landing page } \\
\text { - "landing page"); } \\
\text { - video conferencing; } \\
\text { - webinars; } \\
\text { - CRM systems; } \\
\text { - mobile applications; } \\
\text { - social networks; } \\
\text { - other }\end{array}$ \\
\hline Personal contacts & $\begin{array}{l}\text { - emails; } \\
\text { - on-line consultation; } \\
\text { - "live" telephone conversa- } \\
\text { tion; } \\
\text { - other }\end{array}$ & $\begin{array}{l}\text { - Email; } \\
\text { - instant messengers; } \\
\text { - telephone contacts: } \\
\text { direct or through contact centers; } \\
\text { - other }\end{array}$ \\
\hline
\end{tabular}

Using the data in Table 1, it is necessary to develop such a multi-channel digital communication that will take into account the information-analytical needs of each participant in the supply chain. At the same time, not all contacts (points of contact) are equally important for the interacting parties and will lead to the development of relationships and the establishment of long-term relationships. Personal contacts have the greatest impact, which can be carried out both officially and at the level of informal relations in the form of friendships, which take place primarily in social networks, forums, chat rooms, etc. For example, in the field of services such as education, medicine, IT consulting, personal contacts are important, and when selling goods whose characteristics are precisely determined, you can use non-personal contacts.

As for determining the number of communication channels, their number, with the development of information and communication technologies, is constantly growing, but the most popular in Russia are email, web site, social networks, mobile applications.

The ecosystem of digital communications can include cross- or omnichannel IT platforms, each of which has its own advantages and disadvantages. Table 2 shows a comparative analysis of the types of communication channels based on available publications in various sources.

Based on the fact that when creating a multi-channel digital communication, the main thing is the convenience of exchanging information by participants in the supply chain, then the omnichannel approach is the optimal solution. Manufacturers, intermediaries and consumers can communicate with each other in all existing digital channels according to a single standard from any device. 
Table 2. Comparative analysis of digital communication channels.

\begin{tabular}{|l|l|l|}
\hline & Cross-channel & Omnichannel \\
\hline $\begin{array}{l}\text { Brief charac- } \\
\text { teristic }\end{array}$ & $\begin{array}{l}\text { Communications at points of contact } \\
\text { (touch) can be carried out through "cross" } \\
\text { channels. For example, an incoming call is } \\
\text { received by the contact center operator, and } \\
\text { the response is sent to the caller's email }\end{array}$ & $\begin{array}{l}\text { Informational interaction is car- } \\
\text { ried out using any channels that } \\
\text { provide communication using a } \\
\text { single digital platform }\end{array}$ \\
\hline Dignity & $\begin{array}{l}\text { For the implementation of communica- } \\
\text { tions, the integration of digital channels } \\
\text { into a single information and communica- } \\
\text { tion system is not required }\end{array}$ & $\begin{array}{l}\text { Thanks to omnichannel interac- } \\
\text { tion, the speed of information } \\
\text { flows increases, it is possible to } \\
\text { save information for further con- } \\
\text { tacts }\end{array}$ \\
\hline $\begin{array}{l}\text { Disad- } \\
\text { vantages }\end{array}$ & $\begin{array}{l}\text { For each of the communication channels, } \\
\text { different technologies are used and contacts } \\
\text { are carried out by different employees, for } \\
\text { example, a contact center and the client must } \\
\text { repeat his question or describe the problem } \\
\text { again each time. This can lead to loss of in- } \\
\text { formation and adversely affects the mutual } \\
\text { satisfaction of participants in the supply } \\
\text { chain. }\end{array}$ & $\begin{array}{l}\text { A more complex IT platform and, } \\
\text { therefore, more expensive to im- } \\
\text { plement and use. } \\
\text { It is necessary to develop a } \\
\text { "seamless" digital platform that } \\
\text { combines all the communication } \\
\text { channels of the supply chain par- } \\
\text { ticipants. }\end{array}$ \\
\hline
\end{tabular}

\section{Discussion}

The main advantage of cross-channel interaction is the lack of the need to create a single "seamless" digital platform, which saves the money of participants in the supply chain.

The main advantage of cross-channel interaction is the lack of the need to create a single "seamless" digital platform, which saves the money of participants in the supply chain. In conditions of intense competition, omnichannel digital communication is more preferable, since it takes into account the interests of users and increases their satisfaction due to the ability to receive relevant information.

\section{Conclusion}

1. To create an effective online information exchange system, models are proposed (Fig. 1 and Fig. 2) for organizing digital communication in the supply chain using the main and local IT communication platforms. The development of information and communication technologies makes it possible to digitally transform the business processes of participants in the supply chain, providing information exchange using multi-channel IT platforms. The longer the distribution channels, the more difficult it is to carry out communications between participants in the supply chain. If the supply chains in the B2B market are most often quite short, then in the B2C market they are multi-level and include various wholesale (for example, distributors and sub-distributors) and retail intermediaries, and this leads to the breaking of the information exchange channels necessary to carry out logistics, financial and marketing tasks.

2. The principles of the formation of digital communications of the supply chain are formulated and disclosed, including:

- The principle of software congruence;

- The principle of the backbone of the information and communication system;

- The principle of digital trust between all participants in the supply chain; 
- The principle of multi-channel digital communication.

These principles can serve as a basis for the development of a scientifically based methodology for designing multi-channel digital communications between participants in the supply chain.

3. Based on a comparative analysis, recommendations are given on the choice of digital communication channels in the form of cross-channel or omnichannel IT platforms. The introduction of multichannel digital communications will allow for more mobile exchange of information in the supply chain, increase satisfaction and loyalty of the final link of the supply chain - consumers.

4. The content and the role of digital trust in the use of digital communication are disclosed, which is an important eleme nt in the formation of partnerships between participants in the supply chain in the digital environment.

\section{References}

1. O. Kalinina, L. Alekseeva, D. Varlamova, S. Barykin, I. Kapustina, E3S Web of Conferences 110, 02103 (2019).

2. I. Aleksandrov, M. Fedorova, Proc. of the Int. Science Conf. SPbWOSCE-2017, 211-215 (2017).

3. V. Vilken, O. Kalinina, S. Barykin, E. Zotova, IOP Conference Series: Materials Science and Engineering, (2019) DOI: 10.1088/1757-899X/497/1/012037

4. I. M. Zaychenko, O. V. Kalinina, S. S. Gutman, Proceedings of the 28th International Business Information Management Association Conference - Vision 2020: Innovation Management, Development Sustainability, and Competitive Economic Growth, 758-767 (2016).

5. O. Ayan, M. G. Ozturk, A. M. Koseoglu, M. Colak, Journal of Management, Marketing and Logistics (JMML) 5(4), 311-323 (2018).

6. R. Sousa, C. Voss, J. Serv. Res. 8(4), 356-371 (2006).

7. N. Beck, D. Rygl, J. Retail. Consum. 27 170-178. (2015).

8. J. Bloemer, K. de Ruyter, European Journal of Marketing, 32 (5/6) 499-513. (1998).

9. L. Cao, L. Li, Journal of Retailing 91(2), 198-216 (2015).

10. D. S. Davé, M. J. Dotson, J. E. Stoddard, International Journal of Logistics Systems and Management 31(3), 387-401 (2018).

11. H. A. Nimeh, A. B. Abdallah, R. S.. Lean, Supply Chain Management Practices and Performance: Empirical Evidence from Manufacturing Companies. International Journal of Supply Chain Management (IJSCM) 7(1), 1-15 (2018).

12. D. Herhausen, J. Binder, M. Schoegel, Journal of Retailing 91(2), 309-325 (2016).

13. V. N. Naumov, The first international conference «Business Management in the Digital Economy»: compilation of abstracts, 198-205 (St. Petersburg. Publishing house of St. Petersburg University, 2018).

14. G. Cook, J. Direct, Data Digital Mark. Pract. 15(4), 262-266 (2014).

15. P. Verhoef, P. Kannan, J. Inman, J. Retail. 91(2), 174-181 (2015).

16. J. Zhang, P. Farris, J. Irvin, T. Kushwaha, T. Steenburgh, B. Weitz, Interactive Marketing 24(2), 168-180 (2010).

17. GfK Study: Internet Penetration in Russia: https://www.gfk.com/ru/insaity/pressrelease/issledovanie-gfk-proniknovenie-interneta-v-rossii/. 
18. E. Payne Manser, J. Peltier, V. Barger. Journal of Research in Interactive Marketing 11 (2), 185-197 (2017). https://doi.org/10.1108/JRIM-08-2016-0091.

19. H. Cassab, D. MacLachlan. J. Serv.Manag. 20(1), 52-75 (2009).

20. I. Melero, F. Javier Sese, P. Verhoef, Universia Bus. Rev. 50, 18-37 (2016).

21. S. Heitz-Spahn, J. Retail. Consum. Serv. 20(6), 570-578 (2013).

22. N. Ajith, Infographic, Business research, 69(3), 1032-1045 (2015).

23. C. Dennis, E. Alamanos, S. Papagiannidis, Journal Business Research 69(3). 10611070 (2016).

24. H. Liu, K. Azhandeh, X. Foy, R. Gazda, 69-75. (2019).

25. https://www.pwc.ru/ru/assets/pdf/dti_ru.pdf 